\title{
Revista Portuguesa de Filosofia
}

ISSN 0870-5283; 2183-461X

\section{Provided for non-commercial research and education use.}

Not for reproduction, distribution or commercial use.

\section{The Distinction Between Physics and Metaphysics in Duhem's Philosophy}

Miranda Vilchis, Rogelio

\section{Pages $85-114$}

ARTICLE DOI 10.17990/RPF/2018_74_1_0085

Pierre Duhem e Ernst Mach: Ciência e Filosofia

Pierre Duhem and Ernst Mach: Science and Philosophy

María de Paz; Antonio Augusto Passos Videira; Álvaro Balsas, SJ (Eds.)

74, Issue 1, 2018

ISSUE DOI 10.17990/RPF/2018 74 10000

Your article is protected by copyright (C) and all rights are held exclusively by Aletheia - Associação Científica $e$ Cultural. This e-offprint is furnished for personal use only (for non-commercial research and education use) and shall not be self-archived in electronic repositories. Other uses, including reproduction and distribution, or selling or licensing copies, or posting to personal, institutional or third party websites are prohibited.

If you wish to self-archive your article, contact us to require the written permission of the RPF's editor. For the use of any article or a part of it, the norms stipulated by the copyright law in vigour are applicable.

Authors requiring further information regarding Revista Portuguesa de Filosofia archiving and manuscript policies are encouraged to visit: http://www.rpf.pt

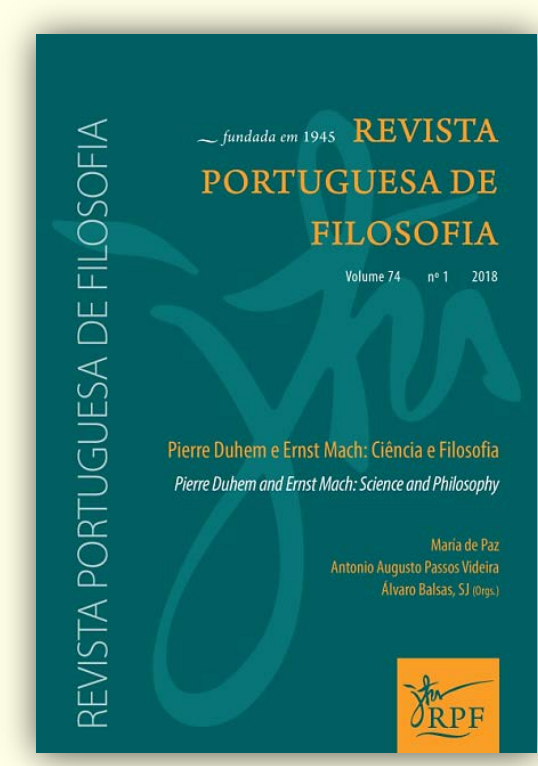




\title{
The Distinction Between Physics and Metaphysics in Duhem's Philosophy
}

\author{
ROGELIO MIRANDA VILCHIS*
}

\begin{abstract}
Pierre Duhem's philosophy of science has influenced many philosophers in the twentieth century, and even today. Many of the subjects he addressed are still highly discussed today, especially the distinction between science and metaphysics. My aim in this paper will be to motivate a naturalistic approach where the difference between physics and metaphysics is only a matter of degree. I focus on whether it would be possible to articulate this gradual distinction from a duhemian point of view. Although Duhem thought that metaphysics is an entirely different and more excellent activity than physics, I believe that Duhem's philosophy of science also supports a naturalistic distinction in terms of degrees. I offer three reasons to justify this conclusion: (i) Duhem's notion of common sense; (ii) Duhem's holism and his views on the generality of our theories, and (iii) Duhem's notion of natural classification. At the end of the paper I will argue that a naturalistic approach accomplishes must of what Duhem wanted to achieve with his distinction.
\end{abstract}

Keywords: distinction, Duhem, gradual, metaphysics, physics.

\section{Introduction}

ccording to Duhem, physics and metaphysics, particularly physical $\Delta$ theory and metaphysical theory, are independent activities: "there 1 is a distinction in kind between metaphysics and physics." ${ }^{1}$ Physical theory cannot explain, which in Duhem's terminology amounts to claim that it cannot tells how reality is in the most profound sense. Nonetheless, Duhem did not dismiss metaphysics (as was done by the positivists) as a meaningless enterprise, rather he understood metaphysics as an autonomous activity even greater in its excellence. He did it mainly for religious reasons. He supported a distinction between science and metaphysics with the objective to guard religious metaphysics from what appeared to

* Universidad Nacional Autónoma de México.

$\triangle$ rogeliomv0101@gmail.com

1. Pierre Duhem, "Metaphysics and Physics," in Essays in the History and Philosophy of Science, ed. and trans. Roger Ariew and Peter Barker (Indianapolis: Hackett Publishing Company, Inc., 1996), 29-49.. 
him unwarranted extensions of scientific principles. He opposed the view that "no sensible person could accept the validity of science and believe in the dogmas of religion at the same time." 2

In this paper, I will argue that some of our physical claims and concepts, through which we understand reality, have the status of metaphysical claims. This is due to the nature of these concepts: their generality, which increases as a function of the amount of the application of the cognitive processes of abstraction (understood as elimination of details) and idealization (understood as the addition of details). So that it is not entirely right that metaphysics is completely distinguished from physics. Rather, we must see this distinction as matter of degree. We often call "metaphysical" the most theoretical statements we make, and "physical" the most concrete ones. But we lack clear criteria which supports a clear-cut distinction. Nonetheless, this gradual distinction would not undermine Duhem's intuitive distinction, nor despise religious metaphysics as a meaningless activity. This partial agreement with Duhem is accomplished by the very general nature of metaphysical assertions and concepts.

I will proceed as follows: first, I will present the reasons Duhem has to distinguish physical theory from metaphysical theory. I will argue that Duhem entertains some views which do not imply this distinction. Although "it is not difficult to cobble together quotations form Duhem's writing that make him sound as though he was uncompromisingly opposed to realism of any kind," ${ }^{3}$ I think his writings give us the opportunity to view physical theory as a continuous approximation to the true nature of reality. Then, I will develop two duhemian theses: common sense and the general and holistic nature of physical theories. These theses, I think, undermine the aforementioned distinction, but motivate another kind of division: a gradualist and continuist one. In section 4, I will discuss why the duhemian notion of "natural classification" supports a gradualist and continuist view. Finally, I will show that a gradual distinction preserves most of what Duhem wanted to derive from his basic tenets.

2. Pierre Duhem, "Letter to Father Bulliot, on Science and Religion," in Essays in the History and Philosophy of Science, ed. and trans. Roger Ariew and Peter Barker (Indianapolis: Hackett Publishing Company, Inc., 1996a), 157-162.

3. Andrew Lugg, "Pierre Duhem's Conception of Natural Classification," Synthese 83, no. 3 (1990): 416. 


\section{The Inaccessibility of Metaphysics}

Duhem is well known by his contributions to thermodynamics and physical chemistry. Among other things, he gave the first clear definition of a reversible process in thermodynamics, the first general proof of the Gibbs phase rule, and the Duhem-Margolis equations. He was also a remarkable historian of physics, known for his work on the continuity between medieval and modern science. But he is better known for his contribution and influence on the philosophy of science. Some of his main theses continue to be highly discussed. In effect, today, many of his theses (often found in his masterpiece "The Aim and Structure of Physical Theory") have been modified and refined by many philosophers to support their own views on varied philosophical subjects. For example, his holistic conception regarding the testing of physical theories (extended by Quine to all domains of inquiry, in his "Two Dogmas of Empiricism." ${ }^{4}$ It was also espoused by Einstein. Howard ${ }^{5}$ observes that because of duhemian philosophy, Einstein eventually became dissatisfied with positivism); his thesis of the underdetermination of theory by the observable data (also extended by Quine ${ }^{6}$ and employed as a premise to justify the importance of talent, creativity, etc., in the construction of scientific theories by Feyerabend ${ }^{7}$ and Lakatos $^{8}$ ), and his distinction between physics and metaphysics (and more generally, between science and philosophy. This thesis had some influence on the views of the logical empiricists concerning the unverifiability of metaphysical claims. It also had an impact on instrumentalist and antirealist positions).

We can find Duhem's view on the necessity to distinguish physics from metaphysics in many of his works "Some Reflections of the Subject of Physical Theories"; "The English School and Physical Theories"; ${ }^{10}$

4. W. V. Quine, From a Logical Point of View (New York: Harper Torchbooks, 1961), 20-46.

5. Don Howard, “Einstein and Duhem," Synthese 83, no. 3 (1990): 363-384.

6. Ibid. See also W. V. Quine, Pursuit of Truth (Cambridge, Mass: Harvard University Press, 1992).

7. Paul Feyerabend, Against Method. (London: New Left Books, 1975).

8. Imre Lakatos, "Falsification and the Methodology of Scientific Research Programmes," in Criticism and the Growth of Knowledge, ed. Imre Lakatos and Alan Musgrave (Cambridge: Cambridge University Press, 1970), 91-196.

9. Pierre Duhem, "Some Reflections on the Subject of Physical Theories." in Essays in the History and Philosophy of Science, ed. and trans. Roger Ariew and Peter Barker (Indianapolis: Hackett Publishing Company, Inc., 1996e), 1-28.

10. Pierre Duhem, "The English School and Physical Theories," in Essays in the History

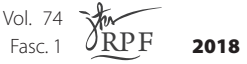


"Physics and Metaphysics," his main work "The Aim and Structure of Physical Theory,"11 and many others. Duhem argues that physics is a discipline, a kind of theoretical discourse, which is independent of metaphysics. This follows from the fact that physics is concerned specifically with observable facts and their nomological joining. It is "A system -a symbolic construction- designed to summarize in a small number of definitions and principles a set of experimental laws."12

Metaphysics, on the other hand, is concerned with the very nature of those facts. In Duhem's terminology, metaphysics is the investigation of the essence of things in their function of being the cause of physical phenomena. This coupled with the study of living things constitutes what he calls "cosmology":

Physics is the study of phenomena arising from brute matter and of the laws that govern these phenomena. Cosmology seeks to understand the nature of brute matter, considered as the cause of phenomena and as the foundation of physical laws. ${ }^{13}$

Duhem explicitly equates cosmology with peripatetic physics: the study of the motion of material things. Of course, physicists do not speak of changes from potential to actual, but "motion" is a reappearing concept in physics. Clearly, there are differences in the kind of categories the ancient philosophers and the modern physicists make use of. The ancients were not interested in discovering laws in its modern sense, nor were they interested in the mathematization of physical concepts (except for astronomy), which is now crucial in the construction of physical theories.

The aversion Duhem felt to any attempt to extract metaphysical conclusions from physical theories resulted in his rejection of mechanical models, ${ }^{14}$ and his skepticism about atomistic ontology. He saw them as attempts, or at least misleading theoretical tools, to uncover the real nature of things: their essence. He recommended physicists to acknowledge the real abstract and general nature of physical theory, from which it follows not a true description of reality, but an interpretation of it. To the extent

and Philosophy of Science, ed. and trans. Roger Ariew and Peter Barker (Indianapolis: Hackett Publishing Company, Inc., 1996f), 50-74.

11. Pierre Duhem, The Aim and Structure of Physical Theory. 2nd ed. and trans. Phillip Wiener (Princeton: Princeton University Press, 1954).

12. Duhem, Some Reflections on the Subject of Physical Theories, 14.

13. Duhem, Physics and Metaphysics, 31.

14. Duhem, The English School and Physical Theories. 
that the human mind puts something of itself into the theory, ${ }^{15}$ it cannot be a completely true description or explanation of reality.

In addition to Duhem efforts to distinguish between physics and metaphysics, he is known for introducing a new way to understand physical theory: their holistic testing. This new perspective has become especially important in the twentieth century. This holism, specially its epistemic form, has influenced thinkers like Quine, ${ }^{16}$ Kuhn, ${ }^{17}$ Lakatos, ${ }^{18}$ and many others. One of the most remarkable consequences of this approach to physics is the thesis that physical theory is underdetermined by the observable data. Of course, there is a big difference between what Duhem thought was underdetermined and its modern versions. For Duhem, underdetermination is restricted to physical theory. This property of physical theory guarantees, argues Duhem, the distinction in question.

Underdetermination is commonly understood as the product of abstraction and interpretation. But it is also the result of the holistic testing of physical theories. Scientific hypotheses are not tested one by one but in conjunction. Presumably, it is theories that are tested as wholes (we will return to this in the next section). So, when testing a hypothesis which is taken to be a relation between physical magnitudes "expressed by mathematical propositions" 19 - if we get unfavorable evidence we cannot tell exactly which hypothesis is wrong. Analogously, we cannot tell exactly which hypothesis is the responsible when we get favorable evidence. This is because all the hypotheses that conform to the theory are, in some way, intertwined to a certain degree. No one in isolation is answerable to the empirical evidence. Only the theory as whole can be tested.

Although this underdetermination is not Duhem's main argument for the distinction between physics and metaphysics, surely it is important to achieve that end. It is important to note that holism (and the generality of the theory) is seen as one consequence of the mathematization of physical theory. Mathematics allows the coordination of raw facts into an organized, systematized and elegant theory. It is also, argues Duhem, a symbolization of the facts. So, in the end, we get a general view of reality, but not of reality as it really is. Being physical theory only an interpretation

15. Duhem, Some Reflections on the Subject of Physical Theories, 11.

16. Quine, From a Logical Point of View.

17. Thomas S. Kuhn, The Structure of Scientific Revolutions. (Chicago: Chicago University Press, 1962).

18. Lakatos, Falsification and the Methodology of Scientific Research Programs.

19. Duhem, Some Reflections on the Subject of Physical Theories, 5.

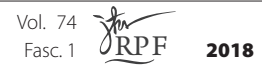


of facts, ${ }^{20}$ it cannot show us the bare truth, but just a modified version of it. The translation of the data by physical theory through mathematical symbolism results in a physical theory with an interconnected internal structure. This formalization of the data has a curious property: there is not a one-to-one correspondence between mathematical formalism and facts. It is also a consequence of the holistic structure ${ }^{21}$ of the theory that it must be tested as a whole.

Despite the presence of underdetermination, Duhem saw a kind of progress in physical theories. A succession of physical theories advances to a better classification of facts. Duhem himself takes a somewhat realist position when he claims that a natural classification can be established "as a sort of image and reflection of the true order according to which the realities escaping us are organized." 22

According to Duhem, physical theory cannot show us the essence of things, their nature. But, in a sense, it can show it indirectly by negation, "through the exclusion of all possible hypotheses except one." ${ }^{23}$ Indeed, it is possible that Duhem had something like a proto structural realism in mind as Psillos ${ }^{24}$ suggests. Despite this, Duhem's position is best understood, I will argue, as suggesting that physical theory just approximates the real description of reality, being just that: an approximation.

From such a standpoint, physics is distinguished from metaphysics. So, metaphysics consists of positive judgements that try to describe reality as it is. In contrast, in describing phenomena, physics can point to what things might be, once it is determined what they are not. This is another way to suggest that physical theories are only approximately true. So, in any case, this approximately-true characterization of physical theories can lead us, as we will see, to view philosophy and science as continuous. This is so because the lack of a clear borderline between both of these disciplines explains why physics approximates metaphysics.

This reference to natural classification allows us to hypothesize that a gradualist and continuist approach is not incompatible with Duhem's

20. Duhem, Some Reflections on the Subject of Experimental Physics, 78. in Essays in the History and Philosophy of Science, ed. and trans. Roger Ariew and Peter Barker (Indianapolis: Hackett Publishing Company, Inc., 1996d), 75-111.

21. Duhem, The Aim and Structure of Physical Theory, 183.

22. Duhem, The Aim and Structure of Physical Theory, 31.

23. Duhem, Physics and Metaphysics, 33.

24. Stathis Psillos, Scientific Realism: How Science Tracks Truth (New York: Routledge, 1999), 38. 
philosophy. Besides his notion of natural classification, we can also find in Duhem's philosophy of science, other indications that metaphysics is not a completely disconnected activity from physics. This philosopher recognizes some role for the study of phenomena in coming to grasp the deep nature of the world. However, knowledge of the substances, which are the cause of those phenomena, are not known completely. Duhem believes that:

When we ascend from effects to causes in order to obtain a metaphysics, starting from some established physical knowledge, as perfect and extensive as one would like, we gain very incomplete and imperfect knowledge of the essence of material things. ${ }^{25}$

Duhem also employs another notion which suggests that physics and metaphysics can be connected: "common sense." It is strongly connected with the notion of "intuition" and "good sense." In speaking about the differences between the French and German minds, he claims that:

Those whose lively good sense allows them to seize upon the truth and intuition as quick as it is accurate are sometimes also those who have the hardest time submitting themselves to the prudent discipline and rigorous deliberateness of the deductive method. On the other hand, those who follow most minutely the rules of the deductive method frequently fail through lack of common sense. ${ }^{26}$

Duhem thought that the relationship between physical theory and common sense was one in which physics went beyond common sense. Physical theory is seen as a kind of interpretation of what is given in common sense. For Duhem, physical science consists in the mere coordination of data, but it does not involve explanation. To explain something implies more, it must explain the real nature of things, but it cannot be accomplished by a mere coordination of facts. Nonetheless, all that physical theory can achieve is to enable us with useful tools to predict phenomena. Physical theory was, for Duhem, a kind of symbolic translation of sensory data.

Duhem also thought that physical theory presupposes common-sense truths. Actually, reasoning through and within common sense implies that we reason through common-sense categories. But, these categories of

25. Duhem, Physics and Metaphysics, 33.

26. Pierre Duhem, German Science, trans. John Lyon (La Salle, IL: Open Court, 1991), 11. 
reasoning usually go beyond what is given in experience. (Famous are the critics of "observation" provided by Hanson" ${ }^{27}$ and Kuhn ${ }^{28}$ ). Interestingly, for Duhem common sense entailed the immediate perception of the general in the particular, ${ }^{29}$ as in "all men are mortal." In effect, this sentence is, for Duhem, "one of the simplest and most certain of common sense laws." 30 As we will see in the next section it is hard to avoid the consequence that our common sense is infected with theory and, as a consequence, with any metaphysical element theory carries with it.

As we have seen, there are some difficulties to establish a clear borderline between physical theory and metaphysical theory. These difficulties spring form Duhem's own views. So, it seems very likely that we can derive some metatheory linking together these two apparently dissimilar theoretical activities.

\section{Holism and Generality}

In this section, I will try to show how physical and metaphysical theories can be understood as a unique continuous theory about the world. My aim is not to argue that this continuist perspective is the only logical consequence we could derive from Duhem's views. My goal is more restricted, I only want to motivate what seems to me a very reasonable consequence stemming from his views. I will focus mainly in the following three duhemian views:

(i) The employment of common sense at the start of scientific inquiry.

(ii) The holistic testing of physical theories and their generality.

(iii) The notion of natural classification.

In this section we will examine the first two. Let us begin with Duhem's advocacy of common sense (i). The duhemian conception of

27. Norwood R. Hanson, Patterns of Discovery (Cambridge: Cambridge University Press, 1958).

28. Thomas S. Kuhn, The Structure of Scientific Revolutions (Chicago: University of Chicago Press, 1962).

29. Jaki, L. Stanley, Uneasy Genius: The Life and Work of Pierre Duhem (Dordrecht: Martinus Nijhoff Publishers, 1987): 321.

30. Duhem, The Aim and Structure of Physical Theory, 165.

vol. 74
Fasc. 1


common allows a link between physics and metaphysics. Common sense presupposes a complex common (or folk) theory, which is partially constituted by concepts that carry a metaphysical load (for example, as we will see, our ordinary concepts "time," "motion," and "body extension" entail a realist attitude about the referents of these terms).

Duhem implicitly endorses a metaphysics when he assumes that our common sense allows us to have contact with objective reality. He was somewhat a realist, to the extent that physical laws and theories,

Were steeped in metaphysics, and in particular in the metaphysics of a commonsense acceptance of external reality and its lawfulness. Duhem endorsed that metaphysics unreservedly and spoke of common sense and of external reality in terms which put his philosophy apart from positivism (Comte), from sensationism (Mach), and from commodism (Poincaré) $\left[\ldots . . . .^{31}\right.$

Nevertheless, Duhem states that: "The experimental method rests on principles evident in themselves and independent of any metaphysics." 32 Undoubtedly, Duhem thought that common sense is independent of metaphysics, but it is hard to think how it can be the case, given the realist meaning (often being implicit rather than explicit) of common sense claims.

Despite this antimetaphysical position, Duhem acknowledges the possibility of bringing these "principles evident in themselves" to the fore of metaphysical scrutiny. But they are analyzed from a metaphysical point of view carried out independently of physics. So, in the end, he saw no relationship whatsoever between physics and metaphysics. Yet, this position does nothing to avoid the introduction of metaphysical elements at the start of the scientific enquiry. We can find many of these elements even in Duhem's description of the procedures of physics.

The experimental method is, for Duhem, independent of metaphysics. It is our primary access to reality, but it does not reveal the true nature of things. This last project belongs to metaphysics. The experimental method only deals with phenomena. The problem is that it seems as if the common sense involved in the experimental method deals with much more than just phenomena. This is because, as Duhem himself states, this method "employs a certain number of concepts, for example, the concepts

31. Stanley, Uneasy Genius: The Life and Work of Pierre Duhem, 320.

32. Duhem, Physics and Metaphysics, 34. 
of 'physical phenomenon' and 'physical law,' 'body extension,' 'time,' and 'motion.' It rests on certain principles, such as the axioms of geometry and kinematics and the existence of laws determining the connection of physical phenomena." ${ }^{33}$ The only reason Duhem offers appeals to the certainty and distinctness with which these concepts appear to us. From this, Duhem derived the following conclusion "The experimental method rests on principles evident in themselves and independent of any metaphysics." 34

And yet, many would agree that these concepts presuppose a metaphysical view. Concepts like "phenomenon," "body," "extension," "time" and "motion" involve some kind of common sense metaphysics. Even if we agree with Duhem that physicists do not ask themselves for the metaphysical meaning of these concepts, one can call into question the duhemian presupposition that metaphysics is here disassociated from physics, especially from the experimental method. Quite the contrary, it is there from the very beginning. (Recently, Paul, L. A. ${ }^{35}$ has advanced a persuasive case for the conceptual and ontological priority of metaphysical concepts over those of the sciences; e.g., those of physics). Our common sense implies a natural perspective about the world, which we can consider "metaphysical." So, it seems unavoidable that, "the adoption of the experimental method itself involves ontological presuppositions." 36

It seems perfectly reasonable that we start from some unanalyzed elements. The problem is that if physical theory begins amid metaphysical presuppositions, then it is difficult to say in which sense, we can be sure about the tenability of the duhemian distinction between physics and metaphysics. It could be objected that one way to avoid this problem is to ensure that the role these metaphysical concepts are doing is reduced to enabling us to begin scientific inquiry. But that these concepts do not play an epistemic or semantic role within physical theory per se. That is to say, it must not form part of the final theoretical product (physical theory). In this vein, Duhem notes that:

33. Ibid., 34.

34. Duhem, Physics and Metaphysics, 34.

35. L. A. Paul, "Metaphysics as modeling: the handmaiden's tale," Philosophical Studies 160, no. 1 (2012): 1-29.

36. Craig Dilworth. The Metaphysics of Science: An Account of Modern Science in Terms of Principles, Laws and Theories. Dordrecht: Springer, 2006.

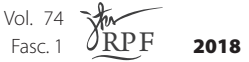


Often illusion inflames human activities more than the clear understanding of the object pursued. Is this reason for confusing illusion with truth? Admirable geographical discoveries have been made by adventurers seeking the Land of Gold. Does this meant that our maps should include El Dorado? ${ }^{37}$

Recently, Morganti and Tahko ${ }^{38}$ have argued that metaphysics and physics develop together in a continuous feedback. Although they think metaphysics is a priori, metaphysics helps physicists to delineate conceptually the starting point of the empirical research. Of course, common sense concepts represent a kind of implicit metaphysics, but Morganti and Tahko try to convince us that fully developed metaphysical concepts are also present. As an example, they bring forward the physical theory of infinite layers of three particles each leading toward Dirac point particles, ${ }^{39}$ prompted by the metaphysical concept of "gunk." So, metaphysical concepts like this play an enabling role, which, nonetheless, preserves the autonomy of physics from metaphysics.

The theory advanced by Morganti and Tahko seems to be very good at explaining the relationship between physics and metaphysics. This theory implies that any metaphysics is heuristically valuable, but independent of physics. This metaphysics, includes any metaphysical notion imbued in common sense. Yet, there is still the possibility that the relationship between these activities be more than just the enabling role attributed to metaphysics. I suspect that physical theory can be carried out more or less independently of metaphysics, assuring a relative autonomy to the latter (as Morganti and Tahko want), but we can make sense of the distinction in terms of degrees, which will avoid the problem of explaining border cases that a clear-cut distinction must face. But before arguing for this, we have to analyze the second duhemian thesis: (ii) the holistic testing of physical theories and their generality.

Holism casts doubt on the hypothesis that the only role of common sense is to enable the production of physical statements, which, in the end, are independent of any metaphysics whatsoever present in common sense.

37. Duhem, Physics and Metaphysics, 49.

38. Matteo Morganti and Tuomas Tahko, "Moderately Naturalistic Metaphysics," Synthese 194, no. 7 (2017).

39. Hans Dehmelt, "Triton, ...Electron, ...Cosmon, ...: An infinite regression?," Proceedings of the National Academy of the Sciences USA, 86, no. 22 (1989): 8618-8619.

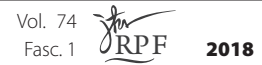


Duhem believed that the holistic property of theories was given only in those which were highly mathematized, and in the narrow scope of the physical sciences. Duhem ${ }^{40}$ emphasized, particularly, the confirmation of physical theories given determined experimental results. These experiments involve the use of the theory as a whole (hence the holism), and if the experiment gives a negative effect, the physicist must follow his good sense when it is necessary to reject one part of the theory, if not the whole theory. The source of error can come from any part of the theory: probably it is due to the impurity of the chemical elements; the perturbations of bodies; the use of non-calibrated or damaged experimental tools; errors in the mechanical models or in the very same physical laws. (It is not that the purity of chemical elements is not theoretical in itself, but its isolation, manipulation, as well as its description depend on a theory. That is why a bad calibrated artifact can be identified as an error in the theory employed in the calibration).

Duhem insists that: "The analysis we have given of experiments in physics shows fact to be completely interpenetrated by theoretical interpretation, to the point that it becomes impossible to express fact, in isolation from theory, in such experiments." ${ }^{41}$ Thus, holism gives way to underdetermination, which evidences the separation of theory from concrete reality. Indeed, due to this detachment, one can build many theories upon the same observational or phenomenal data.

It should be noted that the underdetermination of theory by evidence is not only the result of holism, but also the product of abstraction and generalization. Duhem claims that the physical theory consists in the coordination of experimental laws through theoretical principles and definitions (like "mass," "temperature" and "pressure"). ${ }^{42}$ These have to be even more general principles than experimental laws, if they are going to unify a set of laws under each principle. Furthermore, these principles constitute physical theory. From this, we can infer that there is present a kind of gradual ascension towards generality. In fact, the theoretical statements and theoretical terms that constitute physical theory keep an indirect relationship with the world (which is known to us by our senses), although "each of them has an abstract and symbolic meaning," this

40. Duhem, The Aim and Structure of Physical Theory, 180-218.

41. Pierre Duhem, "Logical Examination of Physical Theory," ed. and trans. Roger Ariew and Peter Barker (Indianapolis: Hackett Publishing Company, Inc., 1996b), 232-237.

42. Ibid., 166. 
meaning, Duhem continues, is "related to concrete realities only by [...] complicated theoretical intermediaries." 43

We must note that there is a direct relationship between holism and generality. The more general becomes our representation of nature, the more interconnected the theoretical elements become. These two facts explain why physical theory is undetermined by evidence. Both are the two sides of the same coin. In fact, it is only when we look into the most general part of the theory that holism becomes apparent. Near the phenomenal level, although not completely deprived of generality, things seem to be less holistic and more responsive to reality individually.

Now, for Duhem, holism is a result of the construction of physical theory, and he takes it to make a distinction between physics and metaphysics. Holism serves to establish a connection beyond that which is presented to us in observational data. Since physical theory is not determined by what is given in experience, our theoretical statements are not a direct access to truth. Physical theory involves something which is unguaranteed by what the world reveals us through experience. Duhem believes that this slack between theory and phenomena is what assures us about the division between physics and metaphysics. This consequence is due to the fact that the physicist mind puts in something of its own into the theory (or "quits" something, through abstraction). This "something" refers, among other things, to the generalization of theoretical principles. For example, physical laws are generalized to apply to most of the known physical phenomena (of course, this also happens in the special sciences like biology, chemistry and the social sciences). Therefore, "physical theory confers on us a certain knowledge of the external world which is irreducible to merely empirical knowledge." 44

This going beyond the phenomena is evident when we connect these laws through theoretical principles. Thus, theory is not a mere reflection of reality, it cannot be a thoroughly accurate description of reality. Indeed, maybe physical theories can never describe and explain us what and how reality is. That is exactly what Duhem thinks. Therefore, concludes Duhem, it is impossible for physics to tell us the true nature of reality. This task corresponds to metaphysics, which by its very nature is detached from physical theory.

43. Duhem, The Aim and Structure of Physical Theory, 190.

44. Duhem, The Aim and Structure of Physical Theory, 312-35.

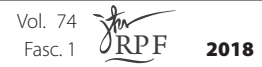


The problem with this characterization of metaphysical theorizing is that it leaves out too much of what we commonly think as "metaphysical assertions." If the general assertions done by physical theory do not constitute metaphysical ones, then some claims about the structure of space and time would be regarded as merely physical statements. But it seems as if the theory of relativity, quantum mechanics, and other physical theories deal in fact with the nature of space, time and particles, etc. It is hard to tell why this kind of claims cannot be counted as metaphysical ones from a duhemian point of view.

In effect, this kind of statements were for Duhem metaphysical in character. Whenever physical theory pronounces on the nature of something, it counts as a metaphysical assertion. But it seems to be the main product of generalization, and, if holism is right, these products of generalization are linked with the more specific parts of physical theory. The result is that there exists a connection between physics and metaphysics.

Although a clear-cut division cannot be provided, this does not prevent us from approximately distinguishing the physical from the metaphysical. In science, we usually ask specific questions like: Do longitude and duration vary as a function of the observer's reference frame? Are time and space related with the distribution of matter in the universe? We ask even more specific ones: Which is the temporal dilation for the observer $o$ ? What is the curvature of spacetime given the material distribution $d$ in a particular part $p$ of the universe? The answers to these questions, if they exist, do not tell us what time and space are. They deal with more concrete matters. On the other hand, asking what space and time is constitute much more general questions, which we tend to call "metaphysical." Nevertheless, the establishment of a precise demarcation seems to be misguided. Consider the following examples.

\section{Generality 1: Time is an entity with properties.}

This characterization is very general. It leaves open the possibility that the category "time" can be multiply realized. It could be an absolute or a relative entity; an entity influenced or not by matter and space; properties can be relational (Leibniz) or absolute (Newton). Also, it can be a psychological projection; the combination of subjective and objective properties, etc.

\section{Generality 2: Time is an entity with specific properties like flux and}

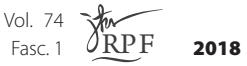




\section{nonrelative simultaneity.}

This view is commonly associated with the metaphysical view about time called "presentism" (which implies the simultaneity of events in any part of the universe. It does not matter whether they are near of faraway). This view leaves us with many possibilities too, but less than generality 1 , the characterization of the category "time" can be multiply realized. Time could or could not form a single entity with space; time could be affected or not by matter and space; it could have relational properties (Leibniz) o absolute ones (Newton). In both generality 1 and generality 2 , our evidence comes, as expected, from our daily experiences, not from physics. Hence, the categories are highly general.

\section{Generality 3. Time is an entity with even more specific properties.}

This time, considering the constraints given by the theories of relativity, the multiple realizability of the category "time" is reduced. We seem to approximate concrete reality. Still, many of the claims made at this stage can somewhat be regarded as "metaphysical." So, the labeling of these claims as "physical" or "metaphysical" is not clearly applicable.

At this level, the evidence consists in the observations and experiments supporting the theories of relativity, e.g., the length contraction and time dilation, ${ }^{45}$ and the deflection of light by the mass of the sun. ${ }^{46}$ Relativity restricts the space of possibilities even more. Thus, it is almost false (we must be aware that science evolves) that time can be an entity independent of space. It is also false that absolute simultaneity exists, therefore presentism is false. Though there could exist a relativized present. ${ }^{47}$ Time could not be an entity independent of space; time could not be an entity independent of the distribution of matter in the universe.

Clearly, these three levels of generality are not exhaustive. There could be much more intermediate levels. Indeed, the theory of relativity in its special and general forms leaves out many possibilities. Also, we can present these levels of generality in terms of statements, models or, as

45. Bailey et al., "Measurements of relativistic time dilation for positive and negative muons in a circular orbit," Nature 268, (1977): 301.

46. M. P. Hobson. et al. "General Relativity: An Introduction for Physicists." (Cambridge: Cambridge University Press, 2006), 230-46.

47. Steven F. Savvit, "There is not Time like the Present (in Minkowski Spacetime)," Philosophy of Science 67 (2000): S563-574. 
Duhem puts it, in terms that begin with experimental laws and culminates in physical theory. But the purpose of this example is only to provide a very rough sketch of how it is quite reasonable that our theories about the world come in degrees of generality, which are connected by holistic links. If this is right then philosophy and science, being important elements in our theories of the world, are not completely differentiated activities. More specifically: physics is not completely divorced form metaphysics in the duhemian sense.

Holism is present in the three kinds of generality presented above. In generality 1, our notions of time and property imply many other concepts, often found in our common-sense theories. Indeed, our common-sense notion of time leaves out it highly vague what the nature of time is. However, generality 2 is nearer to our common-sense notion of time (almost entirely reflected in Newton's theory). We tend to believe in a flowing thing, divisible into past, present and future, with a constant flowing rate which is the same in all parts of the Universe. We cannot understand time without associating it with flux, functioning clocks, the rising of the sun, the change of seasons, our getting old, and with change in general. Many concepts are interrelated here (time, change, clocks, seasons, age, and many others) receiving their justification from our daily experience.

In generality 3 we find a more complex theory, where the achievements of science have impact in metaphysics, although very loosely. Of course, we can discuss much less general theories, but their impact in our general notions will be negligible. The only way they can shed some light on our notion of time is to become more encompassing. And this is attained only through ampliative inferences. But, then, much of the detail will be lost. Undoubtedly, Duhem agrees with this when he claims that "when we ascent from effects to causes in order to obtain a metaphysics, starting from some established physical knowledge, as perfect and extensive as one would like, we gain a very incomplete and imperfect knowledge of the essence of material things." 48

One of the results of holism and generality is that metaphysical statements can be confirmed or infirmed but only in a very tenuous way. That is to say, it is very difficult to confirm a general statement like those dealing with the nature of things. Take the following statement: "space is an absolute entity." Newton maintained that this statement expresses a

48. Duhem, Physics and Metaphysics, 33. 
truth, Leibniz rejected it favoring, instead, a relationist standpoint. In our times it should to be easier to answer this question, but, despite our hopes to establish an answer to this debate, it is not that easy to determine the real nature of space. Even in the light of our most recent physical theories, it seems as if empirical evidence is incapable to resolve the difficulty.

Indeed, we have alternatives where space is not an entity, or an entity quite at odds with our common-sense notion of it. Perhaps, it is a complex of relations, and possibly space can be reduced to geometry. ${ }^{49}$ Maybe, space is curved by the distribution of mass and energy as relativity suggest but still be Euclidean as Lane argues. ${ }^{50}$ Nevertheless, the theory of relativity seems to support to a higher degree the view that space is something out there (the theories of relativity also seem to reject a presentist perspective about time). ${ }^{51}$ Therefore, it is a fact that physics influences metaphysics. In fact, Duhem suggests that "all scientific clarity and certainty are a reflection of the clarity and an extension of these common-sense truths." ${ }^{52}$ Further, it influences the metaphysics present in our common-sense notions, which, in turn, will figure at the start of scientific enquiry. Common sense is specially required at the start of inquiry, at least, to have an idea of what is our object of investigation.

We must also pay attention to the fact that many philosophers have argued that metaphysics consists essentially in the mere systematization of common sense statements. ${ }^{53} \mathrm{I}$ do not believe this is unexpected considering the similarity between physics and metaphysics in their use and production of very general concepts and assertions. As a result of the holistic nature of our theories, common sense is linked to physical theory, because the latter is connected to common sense. As Massey rightly notes, the physicist "insofar as he is interpreting and transposing these commonsense facts "into the ideal, abstract, symbolic world created by the theories he regards as established," his experimental results share the infirmational status of these theories, i.e., they are as subject to D-holism as any theo-

49. John A., Wheeler, Geometrodynamics (New York: Academic Press, 1963).

50. Craig Lane, The Tensed Theory of Time: A Critical Examination (Dordrecht: Kluwer, 2000).

51. Savvit, There is not Time like the Present (in Minkowski Spacetime). See also Morganti Matteo, Combining Science and Metaphysics: Contemporary Physics, Conceptual Revision and Common Sense (London: Palgrave Macmillan, 2013), 147.

52. Duhem, The Aim and Structure of Physical Theory, 104.

53. David J. Chalmers and Frank Jackson, "Conceptual Analysis and Reductive Explanation,” Philosophical Review 110, no. 3 (2001): 153-226.

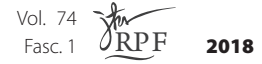


retical hypothesis." ${ }^{44}$ (Here "D-holism" means duhemian holism). We now turn to the last duhemian thesis: "natural classification."

\section{Approximation to the essences of things and natural classification}

So it does not seem that hard to make a naturalistic sense of Duhem views on physical theory. In fact, we can derive a naturalistic, gradualist and continuist conception of physical and metaphysical theories from Duhem's own views on the matter. Indeed, as we will see, we can meet Duhem's worries with this new conception. I have offered two reasons why the distinction Duhem was looking for cannot be accomplished: the role of common sense in physical theories, and holism and generality. But there is a third: the duhemian notion of "natural classification."

According to Duhem, "The order in which theory arranges the results of observation does not find its adequate and complete justification in its practical or aesthetic characteristics, we surmise, in addition, that it is or tends to be a natural classification." ${ }^{55}$ Physics must be "considered in three phases: the observation of facts, the discovery of laws, and the construction of theories." ${ }^{56}$ We approximate the nature of things gradually. First, "the study of phenomena and laws must therefore precede the investigation of causes. In the same way, when one ascends a staircase, the highest step is the one crossed last." ${ }^{7}$ "The mind arrives at the understanding of experimental laws through induction, transforming the facts it has come to understand." 58 Second, we must "study phenomena and establish the laws of succession they follow." Finally, "we must induce from these phenomena the properties of the substances that cause them." ${ }^{59}$ So, "a third phase is conjoined to the two others. This is the theoretical phase." 60

In this third phase "All hypotheses are something other than simple translations of an experimental law. They are the results of a transfor-

54. Gerald J. Massey, "Quine and Duhem On Holistic Testing" American Philosophical Quarterly 48, no. 3 (2011): 248-9.

55. Duhem, The Aim and Structure of Physical Theory, 335.

56. Duhem, Physics and Metaphysics, 30.

57. Ibid., 32.

58. Duhem, Some Reflections on the Subject of Physical Theories, 1.

59. Duhem, Physics and Metaphysics, 31.

60. Ibid., 35-6. 
mation imposed on an experimental law by the mind of a physicist." ${ }^{61}$ This intrusion of the mind is necessary for in the absence of "the systematic connection that speculation establishes among them, the laws given by experimentation form a confused and inseparable mass." 62 One example is the postulation of the aether, where we begin imagining that

the constitution of this medium in such a way that its mechanical properties would be able to form a symbol of all the laws of optics. Color would then be symbolized by the period of a certain vibratory motion propagated in this medium, intensity by the mean kinetic energy of this motion; and the laws of propagation for light, reflection, and refraction would result from the application to this medium of theorems provided by the theory of elasticity. ${ }^{63}$

Beyond the third phase we arrive at the truths of metaphysics, which are "propositions few in number and, for the most part, negative in form, which we obtain in ascending from observed phenomena to the substances which cause them." ${ }^{64}$ His talking of metaphysical truths allows us to establish a connection between physical theory and these truths, because we obtain them precisely in ascending form the observed to the nature of things. At a higher degree of speculation, Duhem claims, we find a metaphysical system. Although Duhem wanted to distinguish metaphysical propositions from metaphysical systems, this distinction must be best viewed as gradual. In fact, Duhem believes that a metaphysical system "is a collection of positive judgements [...] Such a system is acceptable provided none of the hypotheses composing it conflicts with an established metaphysical truth. But it remains always highly problematic and never forces itself on reason in an unavoidable fashion." ${ }^{65}$ In making this assertion, Duhem is prompting a connection between metaphysical truths and metaphysical systems in that the metaphysical system "is acceptable provided none of the hypotheses composing it conflicts with an established metaphysical truth." 66

So, in Duhem's view, physics presents, at least tacitly, different layers of generality. In the second phase, we go beyond the phenomena to the

61. Duhem, Some Reflections on the Subject of Physical Theories, 11.

62. Duhem, Physics and Metaphysics, 26.

63. Duhem, Some Reflections on the Subject of Physical Theories, 12.

64. Duhem, Physics and Metaphysics, 33.

65. Ibid., 33.

66. Ibid., 33. 
experimental laws by induction (at this stage, we usually associate facts with a mathematical structure [often algebraic of geometrical], and we get a physical law). The generalization does not end here. A third phase introduces concepts which serve as summaries of sets of experimental laws. It classifies, organizes and systematizes the great number of dispersed lawful connections between phenomena. Here, Duhem is introducing something similar to a gradualism-continuist approach, except for the fact that he does not seem to recognize the incipient presence of metaphysics at the most theoretical end of physical theory.

In fact, Duhem insists that,

From the knowledge of phenomena, we can draw some knowledge of the things themselves, because they are the efficient causes of these phenomena and because knowledge of an effect provides us with some information of the substance that causes this effect, without giving us, however, a full and adequate knowledge of that substance. ${ }^{67}$

This squares perfectly with the gradualist and continuist view. This does not imply that science gives us complete knowledge of the structure of reality. I agree with Duhem that it is a fundamental fact of science that it cannot offer us a thorough explanation of the world. Be as it may, Duhem gives support to the thesis that: that metaphysics is not completely divorced from physics, except for that generality which characterizes the first. It is very difficult to establish a clear borderline between what counts as physical theory and what as metaphysical theory, when we are expanding our physical principles more and more. Although Duhem did not believe this characterization is correct, he is, in some sense, pointing to a similar view when he claims that "the more hypotheses are separated from the experimental laws that led to their conception, the more physicists have put in themselves into the law's statements." ${ }^{68}$ Is there a reason to make a clear distinction between physical and metaphysical hypotheses? In fact, when choosing between distinct hypotheses, some "can be simpler, and more natural or can translate experimental results more immediately." 69 But, where must we place the dividing line? Duhem does not offer any answer to this question.

67. Ibid., 31 .

68. Duhem, Some Reflections on the Subject of Physical Theories, 11.

69. Ibid., 23. 
As the quote above shows, Duhem acknowledges that there is some approximation to the real nature of things, the real nature of reality. He regularly employs the term "natural classification" to refer to this continual approximation:

Physical theory never gives us the explanation of experimental laws; it never reveals realities hiding under the sensible appearances, but the more complete it becomes the more we apprehend that the logical order in which theory orders experimental laws as the reflection of an ontological order; the data of observations correspond to real relation among things, and the more we feel that theory tends to be a natural classification. ${ }^{70}$

So it is reasonable to claim that "an instrumentalist interpretation of Duhemian epistemology isn't in harmony with an important idea of the French physicist: the physical theory is a natural classification and it slowly progress." 71 It is also true that Duhem allows us to interpret him as endorsing a gradual ascension to things themselves, in the sense that "The physical theory uncovers, at least partially, the veil which conceals the being itself of things." 72 Therefore, "the conviction that physical theory approximates a natural classification is at once the belief that it approximates a true classification. This seems to be in line with the realist's thought that physical theories are, at least approximately, true."73

In any case, we can bring out a layered picture of our theoretical efforts to understand the world. At its most specific and concrete end we can find statements describing and explaining particulars. At the other end of the spectrum we find the metaphysical statements in their full generality. For example, the determinism we encounter in cartesian mechanical metaphysics must be understood as offering us a conception of determinism of a very high level of generality. At the point that determinism goes beyond its restricted application to a particular set of objects confined to a particular location and time, it becomes to some extent a

70. Duhem, The Aim and Structure of Physical Theory, 26-7.

71. Mirella Fortino, "Physics and Metaphysics in Pierre Duhem," Logic and Philosophy of Science 9, no. 1 (2011): 299.

72. Alain Boutot, «Physique et Métaphysique Chez Pierre Duhem, » Les Études philosophiques 2, no. 1 (1994): 248.

73. Karen Merikangas Darling, "Motivational Realism: The Natural Classification for Pierre Duhem," Philosophy of Science 70, no. 5 (2002): 1129.

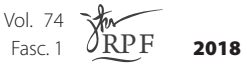


typical metaphysical claim. It is "theoretical and philosophical, to the extent that it is universal." 74

The deterministic laws often apply with great accuracy in the restricted domains, where there are few entities and in circumscribed localizations across space and time. These laws are usually very specific. But, beyond their particular domain of application these laws tend to lose precision; ceteris paribus clauses become more and more important.

It is only in its most general form, in metaphysical theories, that determinism appears to be a metaphysical claim. As was mentioned above, often, when dealing with concrete things, the vocabulary employed seems to be very different from that employed to talk about the world as a whole. For example, when we try to explain the most fundamental structure of reality we usually employ terms like "property," "substance" and "relation." When we describe specific and concrete aspects of the world, as the various sciences try to do, we employ a different set of concepts like "field," "atom," "mammal," "money," etc. Although, these terms are also very general, they are more specific and concrete than the metaphysical ones. But this distinctive vocabulary does not mark a clear distinction between physics and metaphysics. In fact, as Cartwright claims, most of what we say "uses abstract concepts that want 'fitting out' in more concrete ways. Of course, that is compared to yet another level of discourse in terms of which they may be more concretely fitted out in turn."75

It is a fact that to a certain extent we can pursue physics without hard reliance on metaphysics, but this fact is explained by the very generality of the second. The generality of its concepts assures that scientific research, which focuses on the details, is not at odds with our metaphysical views. But, as we have seen, this is a matter of degree. Certainly, scientific research on the nature of time and space has important consequences for our metaphysics, although still in a small degree. These discussions are in the middle of physics and metaphysics. Progress is secured, not because physical research is independent of metaphysics, but because physics is interested in the specific and concrete details. And it is in the details where progress is to be found. I am not suggesting that there is not any kind of progress in metaphysics, but that compared with that of physics, it is minimal.

74. René Poirier, "L'Epistémologie de P. Duhem et sa Valeur Actuelle." Les Études philosophiques 22, no. 4 (1967): 416.

75. Nancy Cartwright, The Dappled World: A Study of the Boundaries of Science. (Cambridge: Cambridge University Press), p. 40. 
Duhem is wrong in trying to establish a borderline between physics and metaphysic so as to secure the first in the path of progress. The internal dissensions of metaphysics cannot produce the same kinds of dissensions in physics, because physical theories can proceed relatively easy apart from the metaphysical ones.

Despite this minimal contact between these disciplines, to advocate a complete independence of one from another is inappropriate, as Duhem does. According to Duhem, these disciplines cannot enter into contradiction, physical propositions cannot "ever be in contradiction with a metaphysical truth," ${ }^{76}$ but this seems inexact. The fact that their interrelationship is very subtle does not mean that they do not enter into contradiction, at least in a negligible way. It is false that the theoretical (often the most theoretical) "in classifying a set of laws [...] adds absolutely nothing to the content of those laws"; 77 that "the physicist cannot and must not accept conflict except with a physicist." 78

So far, I have been criticizing Duhem's conclusion on the grounds that it is more feasible to derive a gradualist and continuist conception of our theories about the world from his own philosophical commitments. Now I will argue that our gradualist and continuist approach resolves some important issues that prompted Duhem to hypothesize a clear-cut distinction between physics and metaphysics.

\section{Duhemian theses from a gradualist and continuist point of view}

The duhemian metascientific and metaphilosophical views tell us something very important about the distinction between metaphysics and physics. And more broadly, between the distinction between philosophy and science. Among his insights, we find: (i) there is pervasive disagreement within metaphysics which cannot be fixed by physics; (ii) physics and metaphysics are somewhat independent activities and theories about the world; (iii) metaphysics is meaningful.

Duhem observes that metaphysics cannot reign over physics, because it is extremely difficult to find agreement in metaphysics. ${ }^{79}$ There is another way metaphysics cannot influence physics, and that is the fact

76. Duhem, Physics and Metaphysics, 36.

77. Ibid., 37.

78. Ibid., 38.

79. Ibid., 34 
that, in Duhem's view, metaphysical systems cannot imply physical laws and particular observations under the scope of scientific analysis. Even if we can, from phenomena, ascend to negative metaphysical judgments, which delineate the real nature of things, we cannot deduce physical observations from a metaphysical system (which, besides being more general, consists of a set of positive metaphysical judgments). This is due to the fact that in defining the nature of things "the view we have of them remains too general and too little determinate, to enable us to foresee the existence of a new class of phenomena or to anticipate a new physical law." ${ }^{80}$ In fact, it seems as if "physics alone can decide if this proposition is correct or incorrect." 81

I agree with Duhem in this respect, but this is due precisely to the fact that metaphysics is more general. Duhem views physics as an activity which must be separated form metaphysics in order for the latter to progress. That is, Duhem sees progress in physics as attainable only if physics is autonomous, because, as we have said, metaphysics seems to lack progress. This is seen as a consequence of the pervasive disagreement between and within the numerous metaphysical systems. Surely Duhem is right in his analysis of this perennial difference in opinion. But the lack of progress derives from the low attention metaphysics puts in the details.

By its very nature, metaphysics is incapable of making the progress we see in the physical sciences. But, there is still likely some progress to be found. For example, it may be argued that the theory of relativity (both, special and general) sheds light on the nature of space and time. From this theory, we seem to be more justified in believing that time and space constitute just one entity: spacetime; that our notion about the present time is inadequate, and that matter affects spacetime. ${ }^{82}$

I find Duhem's observations very helpful for the establishment of what this work tries to demonstrate. If physics and metaphysics are distinguished in the way they are related to the world, and this relation is a matter of degree in function of the generality of theories, then it is not surprise that it is very hard to figure out how metaphysics can influence physics in any way. The converse is also true, how can physics influence metaphysics? But as we have seen, it is possible. The examples about

80. Ibid., 33.

81. Ibid., 34 .

82. Norton, John. 2014. "What Can We Learn about the Ontology of Space and Time from the Theory of Relativity?” in Physical Theory: Method and Interpretation, ed. by L. Sklar. New York: Oxford University Press. 
the nature of space and time show us that the apparent insurmountable differences between the two kinds of theories we are examining can be explained by this appeal to differences in degree.

If the gradualist and continuist view is correct, then Duhem is wrong in thinking that "Metaphysical systems present to us a definition of the nature of things more detailed and more determinate than that furnished by demonstrated metaphysical truths." ${ }^{83}$ It is just an appearance, metaphysical concepts - which compose metaphysical truths- are very general, so, in a sense, they apply to a large set of things (probably each and every one of the entities that populate the universe). To achieve this universality, these concepts have to abstract away and idealize their objects, leading to greater generality. But, they also refer (derivatively) to concrete particulars, being these elements of a set. The cartesian term "extension" is very general, because it refers to a large set of objects, but, at the same time, it refers to each one of the elements of the set. That is why Duhem tells us that metaphysical systems present us a more detailed definition of the nature of things: the general concepts figuring in the metaphysical systems comprise almost any individual in this world. But, in contrast, these general concepts present to us a vague image of each individual in particular. For a concrete and detailed description of a restricted set of objects, or a particular object we would need concrete concepts. In this way, we descend from the most general metaphysical systems through metaphysical principles (and other intermediate principles) to the most concrete representations of the world. One promising candidate for this last role might be fulfilled by the so called "phenomenological models," which, like fables, "transform the abstract into the concrete." 84 These models are more precise and concrete in the description of the world

It is not beyond doubt that "while a physical consequence deduced form some metaphysical propositions participates in the certainty of the latter, a physical consequence deduced from a metaphysical system suffers from the doubtful and problematic character affecting the system itself and cannot be regarded as established." ${ }^{85}$ The problem lies in the distinction between metaphysical propositions and metaphysical systems. It is better seen as a matter of degree.

83. Duhem, Physics and Metaphysics, 33.

84. Cartwright, "The Dappled World: A Study of the Boundaries of Science," 36.

85. Duhem, Physics and Metaphysics, 34. 
Concerning (ii), Duhem pointed out that physics works independently of metaphysics. I think that Duhem is right, although this assertion should be rephrased as: physics and metaphysics are almost independent activities and theories about the world.

This approach also supports the duhemian view that in practice $e^{86}$ a true physics cannot be deduced from the knowledge of the nature of things provided by metaphysics. If metaphysical theories are underdetermined, as I have argued, then many observational consequences could be derived. No unique set of phenomena could be derived from the theory; no metaphysical system could be established as the correct. It also is quite compatible with the duhemian view that, in theory, a true physics could be deduced from metaphysics. But this possibility seems very distant. This is due mainly by the inextricable general nature of our theories about the world.

As it was mentioned in the introduction, Duhem advocated the distinction between physics and metaphysics mainly because he wanted to guard his religious beliefs from attacks coming from the metaphysical principles derived from the scientific ones. But, if the metaphysical claims are localized at the most general part of our theories about the world, then, by its very nature, they are the most immune. They are so vague that empirical evidence has little impact on them. It is extremely hard to envision how to confirm or infirm them. This explains why it seems "absurd to seek among the truth of metaphysics either the confirmation or the refutation of a physical theory," ${ }^{87}$ and it seems impossible to "declare the following proposition true: All physical phenomena are explained mechanically." ${ }^{88}$ It is impossible, Duhem continues, "to declare it false. This proposition transcends physical method." So, given that theological assumptions are metaphysical in character, the empirical evidence has a negligible impact on them.

Another reason why theological truths cannot be threatened lies in the character of these truths. Some of them are considered to be beyond the reach even of our metaphysical principles (the latter derived partially from physical ones). Some are considered to be beyond even of our logic: "the heart has its reasons of which reason knows nothing." ${ }^{89}$ In this sense

86. Duhem, Physics and Metaphysics, 32.

87. Ibid., 37.

88. Duhem, The Aim and Structure of Physical Theory, 273-311.

89. Blaise Pascal, Les Pensées de Pascal (Paris : P. Lethielleux, 1896), 24. 
it is inevitably that the judgements of physics and theology "can neither contradict nor agree with each other." 90

Finally, (iii) is also preserved, although in a slightly different way. Duhem was not a positivist. He did not deny the cognitive importance of metaphysics. He did not take physics to be the only access to reality, as many members of the Vienna circle did. Physical theory and metaphysical theory, each on its own tells us something about reality. In a gradualist and continuist view this is preserved to a certain extent. Physics in its most theoretical part can hardly shows us something about reality, but it is not impossible (as mentioned above about the nature of time and space). So, in this sense, the cognitive quality of metaphysics is preserved.

Perhaps this would not be very satisfying to Duhem, but I leave open the possibility that there exist religious truths which, of course, are beyond the reach of our imprecise metaphysical theories. As we noted above, these truths are often understood as beyond the reach of logic, therefore physics cannot have access to these truths. However, it does not entail that physics is completely detached from the most common metaphysical truths (e.g., about time and space).

\section{Conclusion}

In this paper I proposed to critically analyze Duhem's views on the relationship between physics and metaphysics which, broadly understood, have also implications for the relationship between science and philosophy. Some of Duhem basic tenets such as the physicist reliance on common sense; the holistic nature of physical theories, and the idea of "natural classification" as an ideal to which physical theory constantly approaches, lead us to a rejection of the distinction between physics and metaphysics.

If the analysis is right, then it is reasonable to derive a gradualist and continuist perspective about physics and metaphysics from Duhem own views. Despite appearances to the contrary, the rejection of the distinction between physics and metaphysics does not undermine the basic duhemian theses. After all, the present proposal preserves the essential properties of what Duhem though was the aim of physical theory.

90. Duhem, The Aim and Structure of Physical Theory, 285.

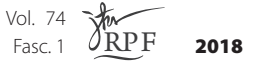




\section{References}

Bayley et al. "Measurements of relativistic time dilation for positive and negative muons in a circular orbit," Nature 268 (1977): 301-5.

Boutot, Alain. «Physique et Métaphysique Chez Pierre Duhem.» Les Études philosophiques 2, no. 1 (1994): 233-248.

Cartwright, Nancy. The Dappled World: A Study of the Boundaries of Science. Cambridge: Cambridge University Press, 1999.

Chalmers, F. David and Jackson Frank. "Conceptual Analysis and Reductive Explanation." Philosophical Review 110, no. 3 (2001): 153-226.

Darling, Merikangas Karen. "Motivational Realism: The Natural Classification for Pierre Duhem." Philosophy of Science 70, no. 5 (2003): 1125-1136.

Dehmelt, H. "Triton, ...Electron, ...Cosmon, ...: An infinite regression?" In Proceedings of the National Academy of the Sciences USA 86, no. 22 (1989): 8618-8619.

Dilworth, Craig. The Metaphysics of Science: An Account of Modern Science in Terms of Principles, Laws and Theories. Dordrecht: Springer, 2006.

Duhem, Pierre. “German Science”. Translated by John Lyon. La Salle, IL: Open Court, 1991.

Duhem, Pierre. "Letter to Father Bulliot, on Science and Religion," In Essays in the History and Philosophy of Science, edited and translated by Roger Ariew and Peter Barker, 157-162. Indianapolis: Hackett Publishing Company, Inc., 1996a.

Duhem, Pierre. "Logical Examination of Physical Theory," In Essays in the History and Philosophy of Science, edited and translated by Roger Ariew and Peter Barker, 232-37. Indianapolis: Hackett Publishing Company, Inc., 1996b.

Duhem, Pierre. "Physics and Metaphysics." In Essays in the History and Philosophy of Science, edited and translated by Roger Ariew and Peter Barker, 29-49. Indianapolis: Hackett Publishing Company, Inc., 1996c.

Duhem, Pierre. "Some Reflections on the Subject of Experimental Physics," In Essays in the History and Philosophy of Science, edited and translated by Roger Ariew and Peter Barker, 157-162. Indianapolis: Hackett Publishing Company, Inc., 1996d.

Duhem, Pierre. "Some Reflections on the Subject of Physical Theories." In Essays in the History and Philosophy of Science, by Pierre Duhem, edited and translated by Roger Ariew and Peter Barker, 1-28. Indianapolis: Hackett Publishing Company, Inc., 1996e.

Duhem, Pierre. "The English School and Physical Theories." In Essays in the History and Philosophy of Science, edited and translated by Roger Ariew and Peter Barker, 50-74. Indianapolis: Hackett Publishing Company, Inc., 1996f.

Duhem, Pierre. The Aim and Structure of Physical Theory. 2nd ed. Translated by Phillip Wiener. Princeton: Princeton University Press, 1954.

Feyerabend, Paul. Against Method. London: New Left Books, 1975.

Fortino, Mirella. "Physics and Metaphysics in Pierre Duhem." Logic and Philosophy of Science 9, no. 1 (2011): 295-303.

Hanson, R. Norwood. Patterns of Discovery. Cambridge: Cambridge University Press., 1958.

Howard, Don. "Einstein and Duhem." Synthese 83, no. 3 (1990): 363-384.

Kuhn, S. Thomas. The Structure of Scientific Revolutions. Chicago: University of Chicago Press, 1962.

Lakatos, Imre. "Falsification and the Methodology of Scientific Research Programs." In Criticism and the Growth of Knowledge, edited by Lakatos Imre and Musgrave, Alan. 91-196. Cambridge: Cambridge University Press, 1970.

Lane, Craig William. The Tensed Theory of Time: A Critical Examination. Dordrecht: Kluwer, 2000.

Lugg, Andrew. «Pierre Duhem's Conception of Natural Classification.» Synthese 83, no. 3

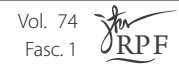

2018 
(1990): 409-20.

Massey, J. Gerald. "Quine and Duhem On Holistic Testing." American Philosophical Quarterly 48, no. 3 (2011): 239-266.

Morganti, Matteo, and Tuomas E. Tahko. "Moderately Naturalistic Metaphysics.” Synthese 194, no. 7 (2017): 2557-2580.

Morganti, Matteo. Combining Science and Metaphysics: Contemporary Physics, Conceptual Revision and Common Sense. London: Palgrave Macmillan, 2013.

Norton, John. "What Can We Learn about the Ontology of Space and Time from the Theory of Relativity?" In Physical Theory: Method and Interpretation, edited by L. Sklar. New York: Oxford University Press, 2014.

Pascal, Blaise. Les Pensées de Pascal. Paris: P. P. Lethielleux, 1896.

Paul, L. A. "Metaphysics as Modeling: the Handmaiden's Tale." Philosophical Studies, (2012): $1-29$.

Poirier, René. “L’Epistémologie de P. Duhem et sa Valeur Actuelle.” Les Études philosophiques 22, no. 4 (1967): 416.

Psillos, Stathis. Scientific Realism: How Science Tracks Truth. New York: Routledge, 1999.

Quine, W. V. From a Logical Point of View. 2nd. New York: Harper Torchbooks, 1961. 20-46.

Quine, W. V., Pursuit of Truth. Cambridge, Mass: Harvard University Press, 1992.

Savvit, F. Steven. "There is not Time like the Present (in Minkowski Spacetime)." Philosophy of Science 67 (2000): 563-574.

Stanley, L. Jaki. Uneasy Genius: The Life and Work of Pierre Duhem. Dordrecht: Martinus Nijhoff Publishers, 1987.

Wheeler, A. John Geometrodynamics. New York: Academic Press, 1963. 
Provided for Personal License use. Not for reproduction, distribution or commercial use.

(c) 2018 by Aletheia - Associação Científica e Cultural. All rights reserved. 